\title{
Editorial: Bark-Water Interactions
}

\author{
John T. Van Stan ${ }^{1 *}$, Anna Klamerus-Iwan ${ }^{2}$ and Salli F. Dymond ${ }^{3}$ \\ ${ }^{1}$ Department of Biological, Geological and Environmental Sciences, Cleveland State University, Cleveland, OH, United States, \\ ${ }^{2}$ Department of Forest Utilization Engineering and Forest Technology, University of Agriculture in Krakow, Kraków, Poland, \\ ${ }^{3}$ Department of Earth and Environmental Sciences, University of Minnesota Duluth, Duluth, MN, United States
}

Keywords: bark, cortisphere, dermosphere, ecohydrology, ecophysiology, epiphytes

\section{Editorial on the Research Topic}

\section{Bark-Water Interactions}

In a winter deciduous forest, bark is essentially all one sees aboveground. One sees a few stubborn, marcescent leaves stuck to branches and few people paying much attention to the bark. Yet, those who have given bark some attention, like William Wordsworth, recognize that "what is gained by the exposure of bark and branches compensates, almost, for the loss of foliage ${ }^{1 \text { " Indeed, the }}$ bark cannot "compensate" for the foliage and its essential ecosystem functions, but it certainly protects the physical and physiological support systems undergirding leaves, while providing critical functions itself. As our perspective discusses, bark is an active and passive player in the water cycle in all wooded ecosystems, all year round, on live and dead plants, and in the litter (Van Stan et al.). Given this, a key question for scientists researching wooded ecosystems is how can bark alter water states, fluxes, and the materials it carries? Moreover, do bark-water physicochemical interactions meaningfully affect the plant's ecophysiological functions, or the structure and functioning of related communities (like corticolous fungi or lichens)? This collection of papers provides new insights into these questions and, thereby, charts exciting opportunities for future research on the "bark side" of the water cycle.

\section{OPEN ACCESS}

Edited and reviewed by: Kevin J. McGuire,

Virginia Tech, United States

*Correspondence:

John T. Van Stan

j.vanstan@csuohio.edu

Specialty section:

This article was submitted to

Forest Hydrology,

a section of the journal

Frontiers in Forests and Global

Change

Received: 26 October 2021 Accepted: 04 November 2021 Published: 26 November 2021

Citation:

Van Stan JT, Klamerus-Iwan A and

Dymond SF (2021) Editorial:

Bark-Water Interactions.

Front. For. Glob. Change 4:802586

doi: 10.3389/ffgc.2021.802586

\section{PHYSICAL AND CHEMICAL INTERACTIONS}

Walking in the woods, forester Peter Wohlleben noticed something peculiar underneath the branches of his favorite beech tree: "The stones were an unusual shape: they were gently curved with hollowed-out areas. Carefully, I lifted the moss on one of the stones. What I found underneath was tree bark. So, these were not stones, after all, but old wood ${ }^{2}$." In this collection, numerous papers give insight into some of the mysteries of bark, particularly how bark interacts with and transports water and solutes (Ilek et al.; Tonello et al.; Oka et al.; Ponette-González; Zabret and Šraj).

This Research Topic begins with the basic (yet difficult-to-answer) question of how much water bark can store during rainfall. Ilek et al. applied a novel bark wetting experiment, finding that patterns in bark water storage: are linked to the amount of water vapor that bark absorbs between storms (i.e., hygroscopic water); can vary with height; and may impact stemflow and/or communities living on/in bark. Zabret and Šraj analyze a data-rich case study (156 storms with intra-storm time series) to describe four different stemflow responses to rainfall, each corresponding with specific meteorological conditions and/or phenophase. And in the most biodiverse savannah in the world, the Brazilian Cerrado, Tonello et al. links stemflow yield to

\footnotetext{
${ }^{1}$ A Guide Through the District of the Lakes in the North of England (5th ed., 1835). Available online at: https://romantic-circles. org/editions/guide_lakes/editions.2020.guide_lakes.1835.html

${ }^{2}$ The Hidden Life of Trees: What They Feel, How They Communicate-Discoveries from A Secret
} World (2016, Greystone Books). 
multiple bark properties rarely measured in ecohydrology, including insoluble lignin content, droplet contact angle and the rate of change as droplets infiltrate into the bark surface. Bark also impacts the quality of draining precipitation water. Focusing on this topic, Ponette-González explores different perspectives and approaches from the past five decades on bark-water interactions. This interdisciplinary synthesis concludes that bark is "an accumulator, transporter, substrate, and reactor." Lastly, Oka et al. (part 1) studied the effects of bark surface structure on stemflow solute concentrations for six tree species in Japanese montane and urban sites. They confirmed some previous findings about bark surface structural influences, showing that current theory on bark structural drivers of stemflow chemistry may be broadly meaningful.

\section{PLANT ECOPHYSIOLOGICAL INTERACTIONS}

The bark is "a proud worker" for the plant, as Jean-Henri Fabre notes, "always tirelessly building cells and renewing her foundations from ruins ${ }^{3}$." Contributions to this collection demonstrate the important roles bark-water interactions can play in plant ecophysiology, in the field (Allen and Connor), lab (Oka et al.), and through data and theoretical synthesis (Berry et al.). In the field, Allen and Connor examined the bark-water interactions of wax myrtle shrubs on coastal hummocks, small islands sitting above mesohaline floodwaters in a freshwater swamp. Their observations suggest these shrubs' stemflow can locally augment net precipitation supply to soils, hypothetically increasing freshwater availability in this stressful environment. In the lab, experiments by Oka et al. (part 2) suggest bark anatomy influences stemflow solute concentrations and composition. They describe new potential linkages between bark anatomical traits and the leaching of common macronutrient ions $\left(\mathrm{Mg}^{2+}\right.$, $\mathrm{Ca}^{2+}$, and $\mathrm{K}^{+}$) by stemflow. These findings have implications for throughfall chemistry, as nutrient leaching from bark occurs along the branchflows that form "drip points." A mini-review by Berry et al. focuses on bark-water-C interactions, discussing how water and $\mathrm{C}$ move between the atmosphere and woody stems. This brief review is packed with a synthesis of current theory and novel analyses relying on large-scale datasets. They assess the climate space where woody stem photosynthesis and bark water uptake may be advantageous and how ubiquitous these processes are across plant families. These field, lab, and synthesis studies construct novel hypotheses and theory, whose testing promise interesting insights into the impacts of bark ecophysiology on the water and nutrient cycling of plants.

\section{ECOLOGICAL INTERACTIONS}

Bark can host abundant lifeforms within a diversity of microhabitats (see Magyar et al.). Indeed, "when compelled by a shower to take shelter under a tree," Henry David Thoreau

\footnotetext{
${ }^{3}$ Translated from: "L'écorce est une fière travailleuse, toujours en fatigue pour faire des cellules et renouveler ses assises en ruines." Histoire de la Bûche: Récits sur la vie des plantes (1867).
}

employed himself "happily and profitably" by examining these lifeforms, "prying with microscopic eye into the crevices of the bark or the leaves or the fungi ${ }^{4}$ " This corticolous community includes microbes, metazoans, and other vegetation, like lichens and bryophytes (Hembre et al.; Magyar et al.; Porada and Giordani). Hembre et al. shows how variable the biomass of nonvascular epiphyte communities can be across a temperateboreal ecotone, $9-900 \mathrm{~kg} \mathrm{ha}^{-1}$, and how much water this biomass can store, $0.003-0.38 \mathrm{~mm}$, while highlighting challenges to estimating epiphyte contributions to canopy hydrology. Porada and Giordani focus on the influence of bark hydrology on corticolous lichens, applying a process-based model (LiBry) with site-level data in Sardinia (Italy). Switching off bark water storage in the model had striking impacts on nutrient cycling (reducing lichen NPP by 21\%) and the community structure (changing morphological traits and reducing physiological diversity by $23 \%)$. These results suggest bark hydrology can be important to the growth and morphology of lichens (at their site), and provides ample justification for future work to quantify interactions between bark hydrology and epiphytic vegetation elsewhere. The collection also includes work on fungi not engaged in lichen symbiosis. Magyar et al. reviews the past 50 years of literature on fungal spores (conidia) washed down the bark in stemflow. This synthesis of observations were analyzed to discuss emergent hypotheses regarding the roles of stemflow fungi in tree health and to identify a hitherto unnamed paraphyletic group: "dendronatant fungi." Clearly, future research on life-bark-water interactions is merited across scales, from microscopic fungi to regional epiphytic communities.

\section{SUMMARY}

Bark-water interactions are understudied processes in wooded ecosystems. This collection of research highlights evidence of the important roles that bark can play in controlling the amount of water that is returned to the atmosphere during storms, or makes it to the soil, groundwater, and streams, as well as the chemical makeup of that water. As bark is an important ecosystem component that can have substantial surface area and water storage, it also exerts controls on the biology of the plants themselves and related organisms, from microbes to metazoans.

\section{AUTHOR CONTRIBUTIONS}

All authors listed have made a substantial, direct, and intellectual contribution to the work and approved it for publication.

\section{FUNDING}

Support for JTVS during the editing of this collection was provided by US NSF (EAR-1954907).

${ }^{4} A$ Week on the Concord and Merrimack Rivers (1849). Available online at: https:// gutenberg.org/files/4232/4232-h/4232-h.htm 


\section{ACKNOWLEDGMENTS}

We are deeply grateful to all of the contributors, reviewers, and editors who made this collection possible. JTVS also would like to thank. Julieta A. Rosell, Doug Aubrey, and Saskia Grootemaat for their insightful and inspiring discussions on various topics related to the "bark side" of the water cycle.

Conflict of Interest: The authors declare that the research was conducted in the absence of any commercial or financial relationships that could be construed as a potential conflict of interest.
Publisher's Note: All claims expressed in this article are solely those of the authors and do not necessarily represent those of their affiliated organizations, or those of the publisher, the editors and the reviewers. Any product that may be evaluated in this article, or claim that may be made by its manufacturer, is not guaranteed or endorsed by the publisher.

Copyright (c) 2021 Van Stan, Klamerus-Iwan and Dymond. This is an open-access article distributed under the terms of the Creative Commons Attribution License (CC $B Y)$. The use, distribution or reproduction in other forums is permitted, provided the original author(s) and the copyright owner(s) are credited and that the original publication in this journal is cited, in accordance with accepted academic practice. No use, distribution or reproduction is permitted which does not comply with these terms. 